\title{
Selection of Single-Stranded DNA Molecular Recognition Elements against Exotoxin A Using a Novel Decoy-SELEX Method and Sensitive Detection of Exotoxin A in Human Serum
}

\author{
Ka Lok Hong, ${ }^{1}$ Kailey Yancey, ${ }^{2}$ Luisa Battistella, ${ }^{3}$ Ryan M. Williams, ${ }^{1,4}$ \\ Katherine M. Hickey, ${ }^{1}$ Chris D. Bostick, ${ }^{1}$ Peter M. Gannett, ${ }^{5}$ and Letha J. Sooter ${ }^{1}$ \\ ${ }^{1}$ Department of Pharmaceutical Sciences, West Virginia University, 1 Medical Center Drive, P.O. Box 9530, \\ Morgantown, WV 20506, USA \\ ${ }^{2}$ School of Medicine, WV University, Morgantown, WV 20506, USA \\ ${ }^{3}$ Department of Medical Laboratory Science, West Virginia University, Morgantown, WV 20506, USA \\ ${ }^{4}$ Molecular Pharmacology \& Chemistry Program, Memorial Sloan Kettering Cancer Center, 1275 York Avenue, \\ New York, NY 10065, USA \\ ${ }^{5}$ College of Pharmacy, Nova Southeastern University, Ft. Lauderdale, FL 33328, USA
}

Correspondence should be addressed to Letha J. Sooter; lethasooter@rocketmail.com

Received 8 July 2015; Revised 9 October 2015; Accepted 12 October 2015

Academic Editor: Peirong Jiao

Copyright (C) $2015 \mathrm{Ka}$ Lok Hong et al. This is an open access article distributed under the Creative Commons Attribution License, which permits unrestricted use, distribution, and reproduction in any medium, provided the original work is properly cited.

\begin{abstract}
Exotoxin A is one of the virulence factors of Pseudomonas aeruginosa, a bacterium that can cause infections resulting in adverse health outcomes and increased burden to health care systems. Current methods of diagnosing P. aeruginosa infections are time consuming and can require significant preparation of patient samples. This study utilized a novel variation of the Systematic Evolution of Ligand by Exponential Enrichment, Decoy-SELEX, to identify an Exotoxin A specific single-stranded DNA (ssDNA) molecular recognition element (MRE). Its emphasis is on increasing stringency in directing binding toward free target of interest and at the same time decreasing binding toward negative targets. A ssDNA MRE with specificity and affinity was identified after fourteen rounds of Decoy-SELEX. Utilizing surface plasmon resonance measurements, the determined equilibrium dissociation constant $\left(K_{d}\right)$ of the MRE is between $4.2 \mu \mathrm{M}$ and $4.5 \mu \mathrm{M}$, and is highly selective for Exotoxin A over negative targets. A ssDNA MRE modified sandwich enzyme-linked immunosorbent assay (ELISA) has been developed and achieved sensitive detection of Exotoxin A at nanomolar concentrations in human serum. This study has demonstrated the proof-of-principle of using a ssDNA MRE as a clinical diagnostic tool.
\end{abstract}

\section{Introduction}

Exotoxin A is a virulence factor secreted by Gram negative bacilli bacteria, Pseudomonas aeruginosa [1]. P. aeruginosa has been identified as an opportunistic bacterium that is commonly associated with wound infections, nosocomial lung infections, and respiratory diseases in cystic fibrosis patients $[2,3]$. Due to increasing antibiotic resistance, infections caused by $P$. aeruginosa have been associated with decrease in the quality of life, increased mortality in patients, and significant cost burden in health care systems $[4,5]$.
Upon covalent cleavage of the full length protein, the enzymatically active fragment of Exotoxin A enters host cells [6]. It causes ADP-ribosylation of elongation factor 2 and thus inhibits polypeptide assembly to ribosome and protein translation, causing death of host cells $[7,8]$. Early studies of purified Exotoxin A report an intravenous lethal dose as low as $3 \mu \mathrm{g} / \mathrm{kg}$ in mice or a $\mathrm{LD}_{50}$ of $\sim 10 \mu \mathrm{g} / \mathrm{kg}$ via intraperitoneal injection $[9,10]$. Because of this highly toxic nature, it is essential to treat $P$. aeruginosa infection as early as possible.

However, current diagnosis of $P$. aeruginosa infection largely relies on traditional methods, such as Gram-stain, 
bacterial culturing, biochemical methods, and immunoassays [11]. Though those methods are sensitive and reliable, they require a significant amount of time to confirm infection, prolonging the time between patient clinical presentations and antibiotics treatments. This leads to the initial use of nonspecific broad spectrum antibiotics and increases the selection pressure for antibiotic resistant strains of the bacteria [12]. In recent years, molecular diagnostic techniques have been developed to increase the efficiency of diagnosing $P$. aeruginosa infection. A majority of these new techniques use polymerase chain reaction (PCR) to identify genes in $P$. aeruginosa [13-16]. Although PCR based diagnostic methods are proven to be sensitive, clinical samples presented may have DNA polymerase inhibitor and other contaminants that increase chances of false positive, which means that a greater amount of time is required to purify samples [17]. Another major limitation of PCR is that it cannot detect and monitor levels of virulence factors, such as membrane antigens and toxins [17]. For example, gene code for Exotoxin A production is not expressed constitutively, due to different environmental factors [18, 19]. Previous studies have demonstrated the clinical role of Exotoxin A in the pathogenesis of P. aeruginosa infections [20]. Patients with higher amount of antibodies against Exotoxin A were correlated with better prognosis [21, 22]. This suggests that Exotoxin A is a significant virulence factor of the bacteria and is an important $P$. aeruginosa infection biomarker. However, there is currently lack of regulatory approved Exotoxin A detection methods for diagnosis purpose. Therefore, there is an increasing need to develop new methods to rapidly measure Exotoxin A through molecular recognition and detection, therefore facilitating the diagnosis of $P$. aeruginosa infections.

Systematic Evolution of Ligand by Exponential Enrichment (SELEX) was first described by the Gold laboratory in 1990 [27]. It utilizes an in vitro selection process that identifies Molecular Recognitions Elements (MREs) that have very high affinity and specificity to their target molecules. The selection process of nucleic acid MREs usually begins with a library of $10^{13}$ to $10^{15}$ different single-stranded DNA (ssDNA) or RNA molecules. The library is then subjected to repeating cycles of partitioning and enrichment for molecules that bind to positive target (target of interest) but not to negative targets. Eventually a single MRE is identified with high specificity and affinity to the target of interest that will be useful for its detection.

In this study, a novel variation of SELEX termed DecoySELEX has been utilized for the identification of a singlestranded DNA MRE that binds to Exotoxin A with high affinity and specificity. The advantage of this variation is an increased emphasis on selecting against negative targets. The first negative target, bovine serum albumin (BSA), is selected based on the similarity in structure and amino acid sequence to human serum albumin [28], which is an abundant protein in blood samples. The second negative target, Cholera toxin, served as example of common bacteria virulence factor [29]. The selection scheme is also designed to decrease nonspecific binding to streptavidin and biotin, substrates used in target
TABLE 1: Decoy-SELEX scheme for Exotoxin A MRE selection.

\begin{tabular}{|c|c|c|}
\hline Round & Positive selection $(+)$ & Negative selection (-) \\
\hline 1 & $\begin{array}{l}\text { Immobilized target (IT) } \\
46 \mathrm{hrs}, 50 \mu \mathrm{L}\end{array}$ & $\begin{array}{l}\text { Immobilization substrate } \\
\text { (IS) } 18 \mathrm{hrs}, 50 \mu \mathrm{L}\end{array}$ \\
\hline 2 & IT $24 \mathrm{hrs}, 50 \mu \mathrm{L}$ & IS $22 \mathrm{hrs}, 50 \mu \mathrm{L}$ \\
\hline 3 & IT $18 \mathrm{hrs}, 50 \mu \mathrm{L}$ & - \\
\hline 4 & IT $12 \mathrm{hrs}, 50 \mu \mathrm{L}$ & IS $20 \mathrm{hrs}, 50 \mu \mathrm{L}$ \\
\hline 5 & IT 8 hrs, $50 \mu \mathrm{L}$ & - \\
\hline 6 & IT $5.5 \mathrm{hrs}, 50 \mu \mathrm{L}$ & $\begin{array}{l}\text { BSA immobilized negative } \\
\text { target (INT) } 24 \text { hrs, } 50 \mu \mathrm{L}\end{array}$ \\
\hline 7 & IT $1 \mathrm{hrs}, 50 \mu \mathrm{L}$ & - \\
\hline 8 & IT $1 \mathrm{hrs}, 25 \mu \mathrm{L}$ & $\begin{array}{l}\text { Cholera toxin INT } 18 \text { hrs, } \\
50 \mu \mathrm{L}\end{array}$ \\
\hline 9 & IT $1 \mathrm{hrs}, 5 \mu \mathrm{L}$ & - \\
\hline 10 & IT $5 \min , 5 \mu \mathrm{L}$ & BSA INT 24 hrs, $50 \mu \mathrm{L}$ \\
\hline 11 & IT $5 \sec , 5 \mu \mathrm{L}$ & IS $21 \mathrm{hrs}, 10 \mu \mathrm{L}$ \\
\hline 12 & IT $5 \sec , 5 \mu \mathrm{L}$ & - \\
\hline 13 & $\begin{array}{l}\text { IT } 5 \mathrm{sec}, 5 \mu \mathrm{L} \text {; competitive } \\
\text { elution with } 2 \mu \mathrm{g} \text { free } \\
\text { Exotoxin } \mathrm{A}, 5 \mathrm{sec}\end{array}$ & $\begin{array}{l}\text { IT } 5 \mathrm{sec}, 5 \mu \mathrm{L} \text {; competitive } \\
\text { elution with } 1 \mathrm{mg} / \mathrm{mL} \text { free } \\
\text { BSA, } 5 \mathrm{~min}\end{array}$ \\
\hline 14 & $\begin{array}{l}\text { IT } 5 \mathrm{sec} \text {, competitive } \\
\text { elution with } 1 \mu \mathrm{g} \text { free } \\
\text { Exotoxin } \mathrm{A}, 5 \mathrm{sec}\end{array}$ & 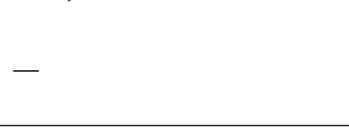 \\
\hline
\end{tabular}

In vitro selection performed for identifying Exotoxin A specific MRE. Immobilized target (IT) is Exotoxin A bound to magnetic beads. Immobilization substrate (IS) is streptavidin-coated magnetic beads blocked with biotin regent. BSA is the abbreviation for bovine serum albumin. Times listed are incubation times in hours (hrs), minutes (min), or seconds (sec).

immobilization. Surface plasmon resonance has been used to characterize the affinity and specificity of the selected MRE. In addition, a modified enzyme-linked immunosorbent assay (ELISA) has been developed by using the selected MRE as the toxin capturing element in human serum and demonstrated the potential use in clinical diagnosis [30-32].

\section{Materials and Methods}

2.1. Decoy-SELEX Method for Selection of Exotoxin A Specific MREs. A single-stranded DNA (ssDNA) library consisting of $10^{15}$ molecules was used to begin the selection of Exotoxin A specific MREs. This library, named RMW.N34, consisted of two 23-base constant regions for primer annealing flanked by a 34-base random region. It was designed by our laboratory and commercially synthesized (Eurofins MWG Operon; Huntsville, AL, USA). A total of 14 rounds of Decoy-SELEX were utilized to enrich Exotoxin A specific MREs (Table 1) and eliminate MREs that bind to negative targets (Figures 1 and 2).

Exotoxin A in lyophilized powder form (List Biological Laboratories; Campbell, CA, USA) was reconstituted in pure water and then covalently biotinylated via Sulfo-NHS-LCBiotinylation (Pierce; Rockford, IL, USA) according to manufacturer's protocol. Biotinylated Exotoxin A was washed with ZEBA Spin Desalting Column (Pierce, Rockford, IL, USA) to remove excess unreacted biotin. Subsequently, biotinylated 


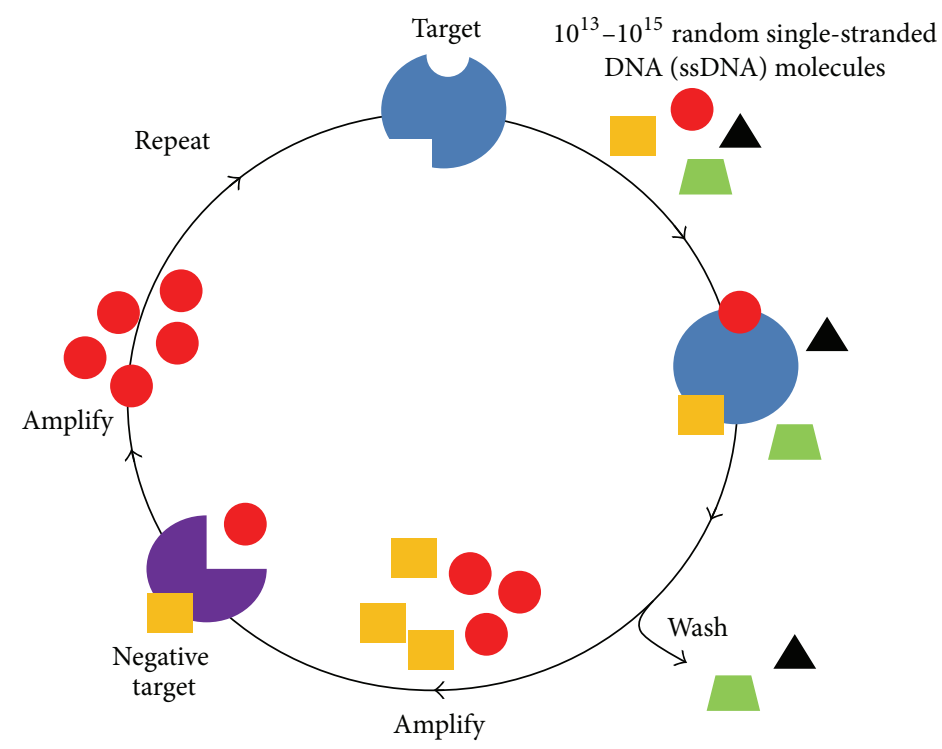

FIGURE 1: Illustration of the Decoy-SELEX process. In vitro selection begins with incubation of target Exotoxin A with a library of $10^{15}$ ssDNA molecules. Binding molecules are amplified and subjected to incubation with multiple negative targets. Molecules that do not bind to negative targets are amplified and carried on to the next round of selection.

Exotoxin A was bound to streptavidin-coated magnetic beads (New England Biolabs, Ipswich, MA, USA) and washed to generate immobilized target (IT) for selections.

In round $1(+)$ of selection, $50 \mu \mathrm{L}$ of IT was incubated with $10^{15}$ copies of ssDNA from the library in a total of $500 \mu \mathrm{L}$ of selection buffer composed of $100 \mathrm{mM}$ sodium chloride, $20 \mathrm{mM}$ Tris- $\mathrm{HCl}$, and $2 \mathrm{mM}$ magnesium chloride (1x selection buffer) at room temperature for 46 hours on rotisserie. After the incubation, the selection mixture was subjected to magnetic separation. Unbound ssDNA was removed and ssDNA-bound to IT was washed with $500 \mu \mathrm{L}$ of selection buffer three times and resuspended in $100 \mu \mathrm{L}$ of selection buffer. This solution containing IT functioned as template for PCR amplification using the following reaction conditions: enriched ssDNA, $400 \mathrm{nM}$ forward and biotinylated reverse RMW.N34 primers (Eurofins MWG Operon; Huntsville, AL, USA) (forward: $5^{\prime}$-TGTACCGTCTGAGCGATTCGTAC-3', biotinylated reverse: $5^{\prime}$-Biotin-GCACTCCTTAACACTGACTGGCT-3'), $250 \mu \mathrm{M}$ deoxynucleotide triphosphates, 1x GoTaq Reaction Buffer (Promega; Madison, WI, USA), 3.5 units of Taq, and pure water. Thermal cycling conditions were as follows: first denaturing at $95^{\circ} \mathrm{C}$ for 5 minutes; cycling at $95^{\circ} \mathrm{C}$ for 1 minute, $63^{\circ} \mathrm{C}$ for 45 seconds, and $72^{\circ} \mathrm{C}$ for 1 minute; and final extension temperature at $72^{\circ} \mathrm{C}$ for 7 minutes. Large-scale PCR ( 2 to $4 \mathrm{~mL}$ ) was performed after each round of positive and negative selection.

After PCR amplification, PCR product containing dsDNA was purified with the GFX PCR purification kit (GE Healthcare, Piscataway, NJ, USA). Eluted dsDNA containing the biotinylated reverse strand was then incubated with streptavidin agarose resin (Pierce; Rockford, IL, USA) for single strand separations [33]. This mixture was transferred into a flow-through column and washed with 5 volumes of 1x phosphate buffer solution. Five volumes of $1 \mathrm{M}$ sodium hydroxide were then added to the column to elute the forward strand of the dsDNA. Subsequently, 0.1 volumes of $3 \mathrm{M}$ sodium acetate at $\mathrm{pH} 5.2,2.5$ volumes of cold $100 \%$ ethanol, and $10 \mu \mathrm{g} / \mathrm{mL}$ of glycogen were added to the eluted ssDNA for ethanol precipitation at $-80^{\circ} \mathrm{C}$. After the solution was frozen, it was then centrifuged at $13,000 \times \mathrm{g}$ for 1 hour. Precipitated ssDNA was subsequently washed with $70 \%$ ethanol and centrifuged at $13,000 \times \mathrm{g}$ for 15 minutes to remove coprecipitated salt. The ssDNA pellet was dried in a vacuum desiccator and resuspended in $50 \mu \mathrm{L}$ of selection buffer. A NanoDrop spectrometer (ThermoScientific; Wilmington, DE, USA) was used to confirm that the suspension contained at least $10^{13}$ copies of ssDNA before proceeding to next round of selection.

Round $1(-)$ was performed by incubating enriched ssDNA from the preceding positive round with immobilization substrate in a total volume of $100 \mu \mathrm{L}$ selection buffer at room temperature for 18 hours on rotisserie. Immobilization substrate was prepared by incubating Sulfo-NHS-LC-Biotin (Pierce; Rockford, IL, USA) with Tris- $\mathrm{HCl}$ and streptavidincoated magnetic beads (New England Biolabs, Ipswich, MA, USA). After magnetic separation, unbound ssDNA served as the template for PCR amplification as illustrated above. Positive rounds 1 to 7 and negative rounds $1,2,4$, and 11 were performed as described with decreasing incubation time in positive rounds and increasing incubation time in negative rounds to increase stringency for selection of MREs specific for Exotoxin A.

Starting with round $6(-)$ of selection, the first negative target, bovine serum albumin (BSA) (Rockland Immunochemical; Gilbertsville, PA, USA), was introduced to the selection. Immobilized negative targets (INT) were prepared identical to IT, substituting Exotoxin A with bovine serum albumin. INT, $50 \mu \mathrm{L}$, was incubated with enriched ssDNA 


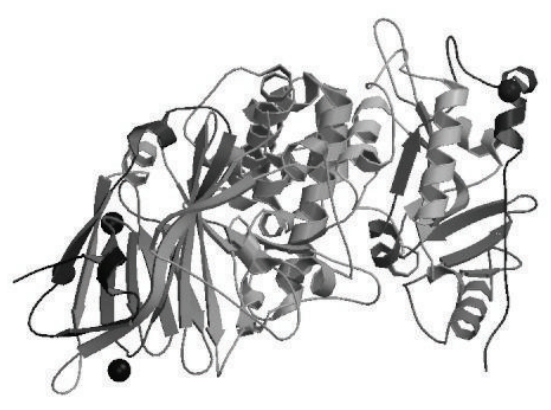

(a) Exotoxin A

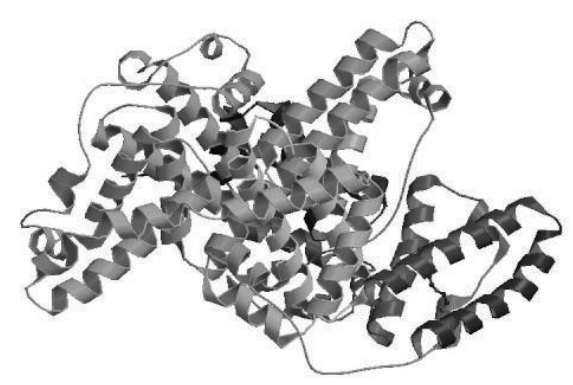

(c) Bovine serum albumin

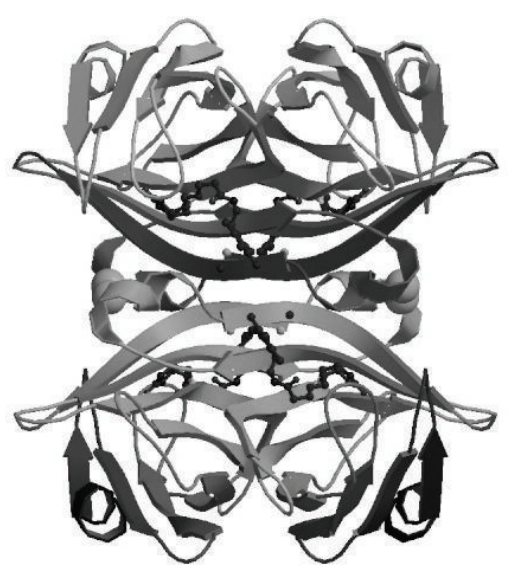

(b) Streptavidin

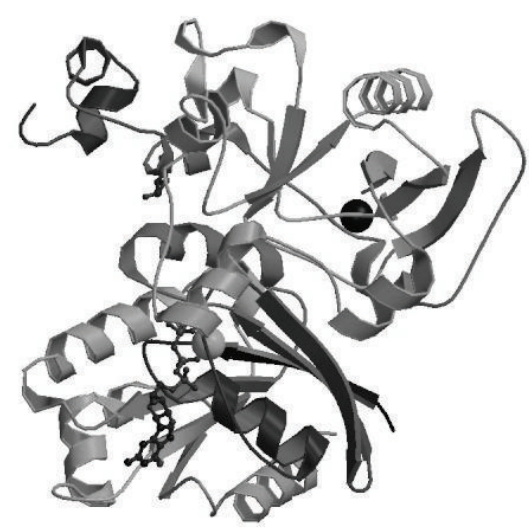

(d) Cholera toxin<smiles>NC(=O)N[C@@H]1[CH]CS[C@H]1CCCCC(=O)O</smiles>

(e) Biotin

FIgURE 2: Structures of targets used in the Decoy-SELEX and SPR cross-binding assays. (a) Ribbon structure of the target of interest, Exotoxin A (PDB 1IKQ, $66 \mathrm{kDa}$ ) [8]. (b) Ribbon structure of streptavidin (PDB 4GJS, $60 \mathrm{kDa}$ ) used in cross bind assays [23]. ((c), (d)) Ribbon structures of bovine serum albumin (PDB 4F5S, 66.5 kDa) and Cholera toxin (PDB 2A5D, 84 kDa) used in negative rounds of selection and crossing binding assays $[24,25]$. (e) Chemical structure of biotin used in negative rounds of selection and cross-binding assays.

from the preceding positive selection round in a total of $500 \mu \mathrm{L}$ of selection buffer at room temperature for 24 hours. Unbound ssDNA was removed with magnetic separation and served as template for PCR amplification. Round 10(-) was performed in the same way. In round $8(-)$, the second negative target, Cholera toxin (List Biological Laboratories; Campbell, CA, USA), was introduced. Preparation of Cholera toxin INT was as described above. Selection conditions were similar to round $6(-)$ with the exception of 18 -hour incubation. This was to ensure that the selected MRE was specific to Exotoxin A and not BSA or Cholera toxin.

Starting with round $8(+)$ of selection, the volume of IT used was decreased in order to increase the stringency of the selection. Rounds 13(+) and 14(+) of IT were subjected to competitive elution with free Exotoxin A solution. IT and the enriched ssDNA were initially incubated for 5 seconds in total of $100 \mu \mathrm{L}$ of selection buffer. IT with bound ssDNA was washed with $500 \mu \mathrm{L}$ of selection buffer three times, then 
$2 \mu \mathrm{g}$ or $1 \mu \mathrm{g}$, respectively, of Exotoxin A in $100 \mu \mathrm{L}$ of selection buffer was added to the mixture and then incubated for 5 seconds. The supernatant obtained from magnetic separation was used as template for PCR amplification. Round 13(-) was performed in the same way using a free BSA competitive elution; however, ssDNA bound to IT was separated and served as PCR template. This was to ensure ssDNA only binds to free Exotoxin A and not to free negative targets.

2.2. Cloning and Sequencing of Exotoxin A Specific MREs. DNA sequencing was performed following rounds $3(+), 6(-)$, $9(+), 12(+), 13(+)$, and $14(+)$ to analyze the ssDNA library for consensus binding sequences. The ssDNA library was amplified with nonbiotinylated primers. It was then ligated into the pCRII vector (Invitrogen, Carlsbad, CA, USA) and transformed into competent $E$. coli bacteria according to manufacturer's protocol. Inserted plasmid was subsequently extracted and purified with the AxyPrep Plasmid Miniprep Kit (Axygen, Union City, CA, USA). The M13R primer, complementary to a region upstream of the PCR insert, was sequenced (Eurofins MWG Operon, Huntsville, AL, USA) along with purified plasmid. A total of 30-50 randomly selected sequences for each respective round were subjected to analysis for consensus sequence families [34, 35].

\subsection{Exotoxin A MRE Binding Assays with Surface Plasmon} Resonance. After analyzing round 14 for its DNA sequences, R14.33 was selected for further characterization. The Mfold DNA web server was used to predict the secondary structure with the following conditions: $25^{\circ} \mathrm{C}, 100 \mathrm{mM} \mathrm{Na}^{+}$, and $2 \mathrm{mM}$ $\mathrm{Mg}^{2+}$ [26]. Subsequently, R14.33 was synthesized by Eurofins MWG Operon with a $5^{\prime}$ amino-C6 modification for use in surface plasmon resonance (SPR) binding assays.

Glass slides $(12 \mathrm{~mm} \times 10 \mathrm{~mm})$ were cleaned by sonication in acetone, isopropyl alcohol, and doubly deionized water (5 min, each) and then blown dry with nitrogen. Gold was evaporated onto the slides using Temescal BJD-2000 system (Edwards Vacuum; Phoenix, AZ, USA) with an Inficon XTC/2 deposition controller (Inficon; East Syracuse, NY, USA) (chamber pressures $\leq 1.0 \times 10^{-6}$ Torr). Samples were rotated $(3 \mathrm{rpm})$ and monitored during deposition for metal thickness (6 MHz quartz piezoelectric crystals, gold-coated) (Kurt J. Lesker Co., Clairton, PA, USA). Rates of $0.3-0.5 \AA / s$ were maintained during the deposition of a titanium adhesion layer $(2 \mathrm{~nm})$ and a gold layer $(50 \mathrm{~nm})$. After that, samples were cooled to room temperature before being removed from the chamber.

The gold slide was then cleaned in $100 \%$ ethanol under sonication for 5 minutes and then placed in a solution containing $10 \mathrm{mM}$ 11-mercaptoundecanoic acid (11-MUA) (Sigma; St. Louis, MO, USA) and $10 \mathrm{mM}$ triethylene glycol mono-11-mercaptoundecylether (PEG3) (Sigma; St. Louis, MO, USA) in a 1 to 5 ratio for 24 hours under argon. After the formation of the self-assembled monolayer (SAM), the gold slide was rinsed with $100 \%$ ethanol, pure water, and blown dry with a slow stream of nitrogen. The prepared gold slide was inserted into the carrying cartridge and docked into a Biacore X100 (GE Healthcare; Piscataway, NJ, USA). The running buffer for immobilization was composed of $100 \mathrm{mM}$ sodium chloride, $20 \mathrm{mM}$ potassium phosphate, and $2 \mathrm{mM}$ magnesium chloride, $\mathrm{pH} 7.56$ (1x immobilization buffer). Next, $100 \mathrm{mM}$ N-hydroxysulfonyl succinimide (sulfo-NHS) (Pierce; Rockford, IL, USA) and $400 \mathrm{mM} \mathrm{1-}$ ethyl-3-(3-dimethylaminopropyl) (EDC) (Pierce; Rockford, IL, USA) were mixed $(1: 1)$ and injected into flow cell 1 and 2 at a flow rate of $5 \mu \mathrm{L} / \mathrm{min}$ for ten minutes for the activation of the carboxyl group of 11-MUA. Then, $300 \mu \mathrm{L}$ of $1 \mu \mathrm{M} 5^{\prime}$ amino modified ssDNA in immobilization buffer (after denaturing at $95^{\circ} \mathrm{C}$ for $5 \mathrm{~min}$ and cooling to room temperature) was injected into flow cell 2 at a rate of $5 \mu \mathrm{L} / \mathrm{min}$. At the end of the DNA injection, unreacted carboxyl groups were inactivated by injection of selection buffer twice for a total of twenty minutes, followed by a regeneration cycle with $45 \mathrm{mM}$ glycine and $100 \mathrm{mM}$ sodium hydroxide in 5\% ethanol (regeneration buffer) for 30 seconds [36, 37].

After immobilization, selection buffer was then used as the running buffer for binding assays. The binding affinity of R14.33 was determined by injecting concentrations of $0,0.5$, $1,1.2,1.4$, and $2 \mu \mathrm{M}$ of Exotoxin $\mathrm{A}$ in flow cells 1 and 2 at a flow rate of $5 \mu \mathrm{L} / \mathrm{min}$ at room temperature. Each cycle comprised a 180 -second wait period, 180-second contact period, 180second wait period, and 30-second regeneration period using regeneration buffer. Assays were performed in duplicate [36, 37]. Kinetic data was analyzed using the Scrubber- 2 software (BioLogic Software; Campbell, Australia) to determine the equilibrium dissociation constant $\left(K_{d}\right)$, assuming a one-toone kinetics model.

To determine the cross-binding activity of R14.33 to negative targets, blank selection buffer and $5 \mu \mathrm{M}$ each of Exotoxin A, BSA, biotin (Sigma; St. Louis, MO, USA), Cholera toxin, and streptavidin (Amresco; Solon, OH, USA) were injected into both flow cells with the same conditions as described above. Each molecule was tested in triplicate. All data was averaged and standard deviations were calculated as previously described [36]. One-way ANOVA and Bonferroni post hoc test were performed to determine statistical differences in the means for analytes.

2.4. Exotoxin A MRE Modified ELISA Assays. A sandwich ELISA assay modified with ssDNA MRE was developed. R14.33 was commercially synthesized with $5^{\prime}$ biotinylation for the use as the antigen capturing element (Eurofins MWG Operon; Huntsville, AL, USA). Streptavidin-coated 96-well plate (Pierce; Rockford, IL, USA) was washed three times for 5 minutes, with $200 \mu \mathrm{L}$ of wash buffer (1x selection buffer, 0.1\% BSA, 0.05\% Tween-20 detergent). Subsequently, $100 \mu \mathrm{L}$ of $40 \mathrm{nM} 5^{\prime}$ biotinylated ssDNA in selection buffer (after denaturing at $95^{\circ} \mathrm{C}$ for $5 \mathrm{~min}$ and cooling to room temperature) was added to sample wells and incubated for 2 hours with shaking at room temperature. Each well was washed three times with wash buffer to remove nonimmobilized ssDNA. A negative control for each replicate consisted of a blank well without immobilized ssDNA. Then, $100 \mu \mathrm{L}$ of each 1x phosphate buffer solution, selection buffer, $100 \mathrm{nM}$ of Exotoxin A in selection buffer, human serum (Sigma; St. Louis, MO, USA), or $100 \mathrm{nM}$ of Exotoxin A in human serum was added to individual sample wells. The plate was incubated for 1 hour with shaking at room temperature. 
Following sample incubation, each well was washed three times with wash buffer to remove unbound Exotoxin A. Next, $100 \mu \mathrm{L}$ of $1: 100$ dilution of primary goat antiExotoxin A antibody (List Biological Laboratories; Campbell, CA, USA) in wash buffer was added to each well and followed by 30 minutes of incubation with shaking at room temperature. Following primary antibody incubation, each well was washed three times. Subsequently, $100 \mu \mathrm{L}$ of $1: 500$ dilution of secondary rabbit anti-goat antibody conjugated to horseradish peroxidase (Pierce; Rockford, IL, USA) in wash buffer was added to each well and incubated for 30 minutes at room temperature with shaking. Lastly, each well was washed five times to remove nonspecifically bound antibodies. Controls without antibodies and with only primary antibodies added were also performed. Assays were performed in quadruplicate.

ABTS substrate (Pierce; Rockford, IL, USA) was added to each well according to the manufacturer's instruction. After ABTS was added, absorbance was measured in a Synergy 2 microplate reader with OD reading at $410 \mathrm{~nm}$ and $650 \mathrm{~nm}$ using Gen5 1.06 software (Biotek US; Winooski, VT, USA) in two-minute increments. All data was averaged and standard deviations were calculated. For each Exotoxin A containing sample, a two-tailed Student's $t$-test was performed to determine statistical differences, respectively, to selection buffer or human serum blank controls at $P<0.05$.

\section{Results and Discussions}

3.1. Selection of Exotoxin A Specific MREs. Fourteen rounds of Decoy-SELEX were performed to identify ssDNA MREs specific to Exotoxin A (Table 1). The selection scheme was aimed to direct the ssDNA MREs to bind to free Exotoxin A in solution and reduce enrichment of nonspecific binding to immobilization substrates, BSA, and Cholera toxin. Initially, 30-50 randomly selected sequences were analyzed for the presence of consensus sequence families after rounds 3, 6, 9, and 12. Toward the end of the selection, in order to monitor the convergence of families more frequently, 30-50 random sequences from both rounds 13 and 14 were analyzed as previously described $[34,35,38]$.

In the round 14 of ssDNA library, there was a noticeable and significant presence of sequence families in one sequence, R14.33 (Table 2). This sequence appeared in about $40 \%$ of the sequence families. R14.33 had one possible predicted structure, with a relatively low Gibbs free energy value of $-9.93 \mathrm{kcal} / \mathrm{mol}$ according to the Mfold prediction. This indicated a relatively stable secondary structure at the given conditions (Figure 3). The variable region of R14.33 also participated in the formation of two stem-loop structures [39]. Therefore, R14.33 was chosen for further characterization.

3.2. Affinity and Specificity of Exotoxin A Specific MRE. Affinity of the selected MRE was determined by SPR binding assays. Assays were performed with Exotoxin A concentration from high $\mathrm{nM}$ to low $\mu \mathrm{M}$ range with at least 2 duplicate concentrations. The equilibrium dissociation constant $\left(K_{d}\right)$ was between 4.2 and $4.5 \mu \mathrm{M}$ (Figure 4 ). In recent years, there have been a number of MREs selected against protein targets which utilized SPR for characterization of binding affinity. Reported equilibrium dissociation constants in these studies range from low-nanomolar to high-nanomolar [4044]. It is to be noted that these studies relied on different immobilization methods compared to what was used here, including streptavidin-biotin linkage and thiolated DNA attachment [41-44]. Also, several studies utilized a sandwich detection method to amplify signals, thus enhancing the limit of detection [42, 45, 46].

SPR cross-binding assays were performed to test the specificity of the selected Exotoxin A MRE. Concentrations of all cross-binding analytes were higher than those used in affinity assays to ensure that R14.33 has no nonspecific binding to negative targets. The method of presentation of the current data as relative response unit of R14.33 to all analytes has been previously described $[36,46]$. Binding responses showed a much higher affinity of R14.33 to Exotoxin A in solution than to all negative targets (one-way ANOVA: $F_{2,12}=$ 573.4, $P<0.001$ ) (Figure 5), and to streptavidin, a significant component of the immobilization substrate. This is noteworthy as streptavidin was present in all of the selection rounds. It is clear that competitive elutions performed in the last two positive rounds gave the ssDNA library selectivity for free Exotoxin A in solution over immobilized target and other negative targets, thus validating the Decoy-SELEX method.

The determined equilibrium binding constant of the selected Exotoxin A MRE is higher than other studies utilizing SPR binding assays. This difference is likely due to different methods of immobilizing the ssDNA MRE as noted above and thus leads to a lower level of immobilization and detection responses. The current study utilizes direct covalent conjugation of $5^{\prime}$ amino modified ssDNA to the SAM on gold surface $[34,35,37]$. However, covalently attached DNA provides a more stable immobilization as compared to streptavidin/biotin and thiolated DNA attachment under a wide range of storage conditions. This is a potential advantage in the real application of a ssDNA MREs based biosensor, as the longevity of the biological probe is a huge determining factor of its application value [47]. It is also important to note that previous study demonstrated a 100-fold higher $K_{d}$ between SPR binding measurements and binding assays relying on free ssDNA in solution [48]. This is likely due to the difference in the availability of binding pockets on MREs that are immobilized on solid platform as compared to being in solution. The SPR setup in this study is also very similar to the potential design of a final sensor. Therefore, this is a very realistic assay and is translational as a sensor.

3.3. Diagnostic Application of Exotoxin A Specific MRE. The Exotoxin A specific MRE demonstrated high specificity and minimal cross-binding activity to BSA. It is reasonable to believe that this low binding property may be extrapolated to human serum albumin [41]. This allowed the investigation of using the selected MRE as a potential diagnostic tool. A sandwich ELISA assay modified with the ssDNA MRE as the toxin capturing element was developed. Reproducible and statistically significant detection of Exotoxin A at $100 \mathrm{nM}$ in spiked human serum samples was achieved compared to negative controls in six independent assays $(P<0.05$ to 


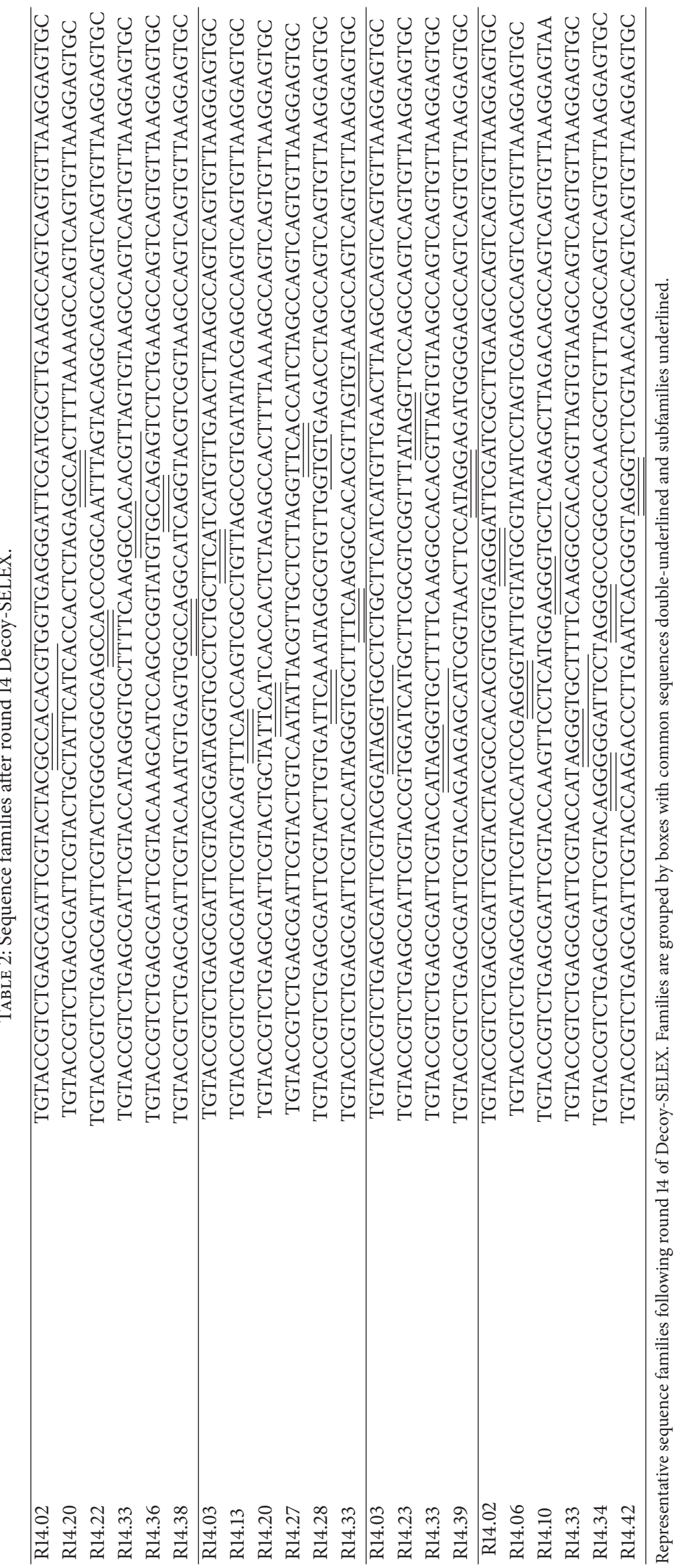




\section{TGTACCGTCTGAGCGATTCGTACCATAGGGTGCTTTTCAAGGCCACACGTTAGTGTAAGCCAGTCAGTGTTAAGGAGTGC}

(a)

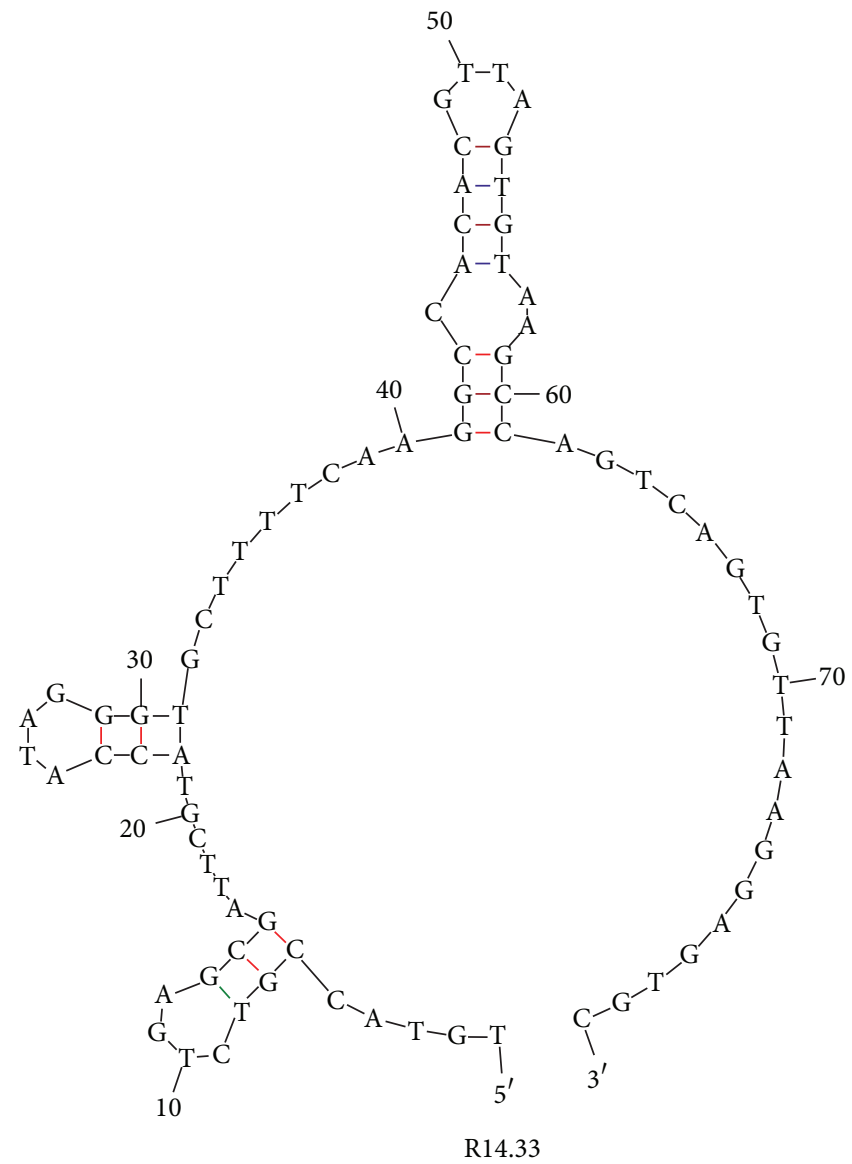

(b)

FIGURE 3: Secondary structure and sequence of R14.33 ssDNA MRE. (a) ssDNA sequence of Exotoxin A MRE R14.33. Gray letters indicate constant regions of the MRE. (b) Mfold prediction of R14.33 secondary structure [26].

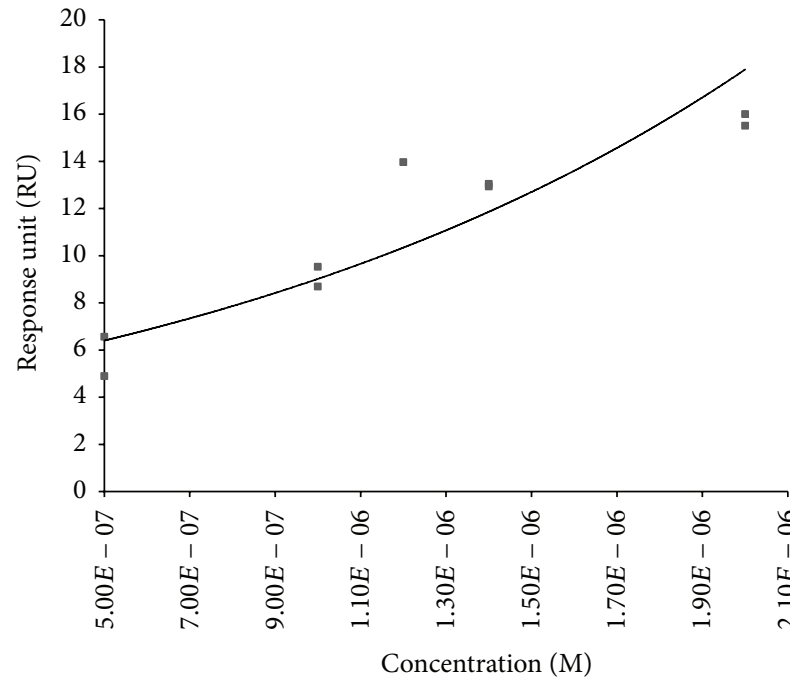

(a)

\begin{tabular}{ccc}
\hline Plot & $K_{d}$ & Std. error \\
\hline 1 & $4.2 \mu \mathrm{M}$ & $3 \mu \mathrm{M}$ \\
2 & $4.5 \mu \mathrm{M}$ & $3 \mu \mathrm{M}$ \\
\hline
\end{tabular}

(b)

FIGURE 4: SPR binding kinetics assays of R14.33. Data represent $K_{d}$ of R14.33 from two binding assays evaluated via Scrubber 2 software (Software; Campbell, Australia). (a) Representative binding response curve of R14.33. (b) Equilibrium dissociation constants and standard error of two binding assays. 


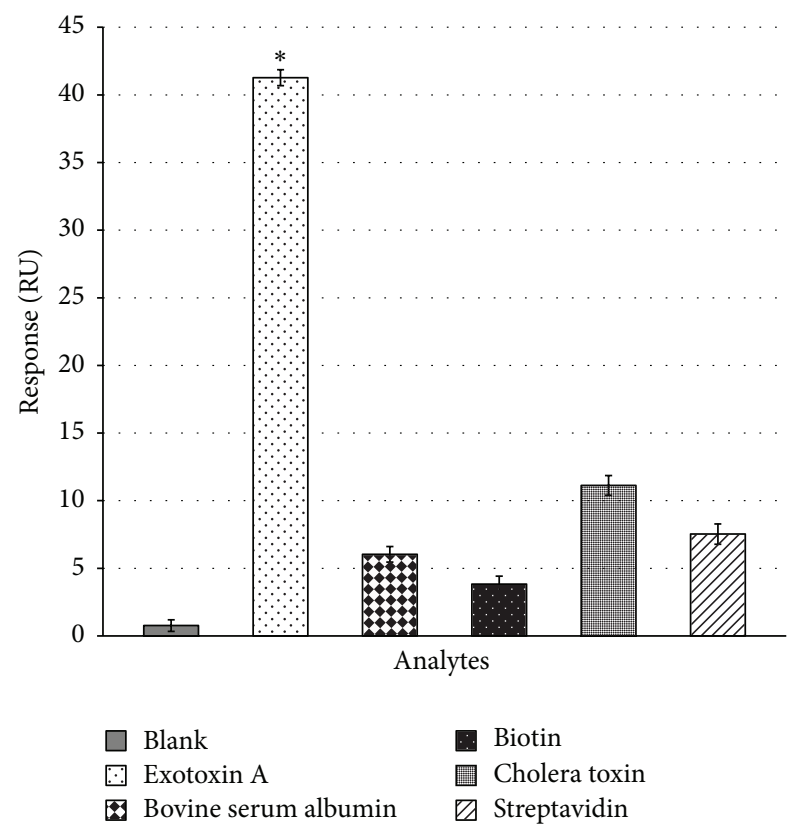

FIGURE 5: SPR cross-binding assays of R14.33. Data represent specificity of R14.33 Exotoxin A MRE. Error bars represent standard deviations of three runs. Statistical significance levels of $P<0.001$ are designated by “*”. The observed significance levels are adjusted by Bonferroni post hoc procedure. Exotoxin A has a significantly higher response when compared to blank control and all other analytes, indicating low cross-binding activities of R14.33. Blank represents $1 \mathrm{x}$ selection buffer. Concentrations of all analytes are at $5 \mu \mathrm{M}$.

$P<0.001$ ) (Figure 6). It has been reported that ssDNA MRE generally has a half-life of 1 hour in human serum due to the presence of exonuclease [49]. Therefore, toxin incubation time that ranged from five minutes to one hour was tested during assay development. While a portion of the immobilized MRE is likely to be degraded in serum condition, the one-hour toxin incubation period yielded the most consistent result and therefore it was utilized in all experimental assays.

Previous study has attempted to incorporate ssDNA MRE into a system for target detection in buffer diluted human serum [50]. Similar ssDNA MRE modified ELISA assay for the detection of bacteria toxins has been previously described $[51,52]$. However, clinically relevant samples were not tested in both studies. It is known that the binding activities of nucleic acid MREs are highly dependent on their three-dimensional structures and are influenced by factors such as temperature, $\mathrm{pH}$, and ionic strength of the binding environment [39]. This leads to challenges in applying nucleic acid MREs in targets' native complex environments, such as human serum [53]. This study demonstrated an improvement to these previous reported studies by showing the robustness of the selected Exotoxin A specific MRE in undiluted serum without any base modifications, and it was able to retain a level of binding activity in an environment that was very much different compared to the selection condition.

Currently, there are limited studies in quantifying the amount of Exotoxin A in vivo. Previous studies showed large differences in the levels of Exotoxin A detected in murine serum (averaged $116.0 \mathrm{ng} / \mathrm{mL}$ ) and in culture media (averaged $1.4 \mu \mathrm{g} / \mathrm{mL}$ ) $[54,55]$. One study showed significant differences in Exotoxin A detected in different patient sputum samples $(0.3 \mathrm{ng} / \mathrm{mL}$ to $126 \mathrm{ng} / \mathrm{mL})$, and as high as $29.3 \mu \mathrm{g} / \mathrm{mL}$ of Exotoxin A was detected in the culture supernatant of sputum isolated $P$. aeruginosa [56]. It has also been reported that blood isolated $P$. aeruginosa produced the highest amount of Exotoxin A in culture conditions (approximately $0.3 \mu \mathrm{g} / \mathrm{mL}$ ) [57]. Overall, these results suggest that in vivo levels of Exotoxin A vary significantly and are not well quantified in human patients.

Historically, an ADP-ribosylation assay has been utilized to quantify the amount of Exotoxin A in research studies [20, $57-60]$. This assay requires the use of radioactive NAD and extensive experimental preparations, and therefore it may not be practical for diagnostic use. Although a traditional antibody-based sandwich ELISA assay (MyBioSource; San Diego, CA, USA) is commercially available with a reported detection range between $0.156 \mathrm{ng} / \mathrm{mL}$ and $10 \mathrm{ng} / \mathrm{mL}$, it was designed for research purposes only. Also, the ranges of Exotoxin A levels in vivo are likely to be wide. The relatively narrow detection range of the commercial ELISA kit may limit its usage in clinical samples. It is to be noted that, in our ssDNA MRE modified ELISA assays, $100 \mathrm{nM}$ or $6.6 \mu \mathrm{g} / \mathrm{mL}$ of Exotoxin A in human serum was detected. While this is highly reproducible, the differences compared to negative controls are small enough to be near the assay's detection limit. Based upon the available clinical data on Exotoxin A level in patients, it is difficult to completely rule out the clinical usage of the current ssDNA MRE modified ELISA assay. In order to transition the current assay into a final product for clinical use, it will likely require modification, optimization, and possibly an industrial partnership for development. Nevertheless, ssDNA MRE modified assay does offer several advantages when compared to ELISA assays that are based solely on antibodies, such as thermostability, and regeneration of assay by a basic buffer wash [61].

Overall, this study has identified a ssDNA MRE with high affinity and specificity for Exotoxin A of P. aeruginosa. To the best of our knowledge, this is the first ssDNA MRE targeting Exotoxin A. The successful use of SPR for MRE characterizations showed the potential of it being incorporated into a SPR-based biosensor for real time, label-free detection of Exotoxin A in biological matrices [41, 42]. In addition, the ssDNA MRE modified ELISA assay offers a potential new way to facilitate the diagnosis of $P$. aeruginosa infection by rapidly identifying the presence of one of the most significant virulence factors. The ELISA requires minimal sample manipulations and approximately two hours from toxin incubation to detection. This method may also supplement direct diagnosis methods based on detecting the presence of bacterial cells through culturing and PCR.

\section{Conclusions}

This study utilized a novel variation of the SELEX process, Decoy-SELEX, to obtain a ssDNA Molecular Recognition 


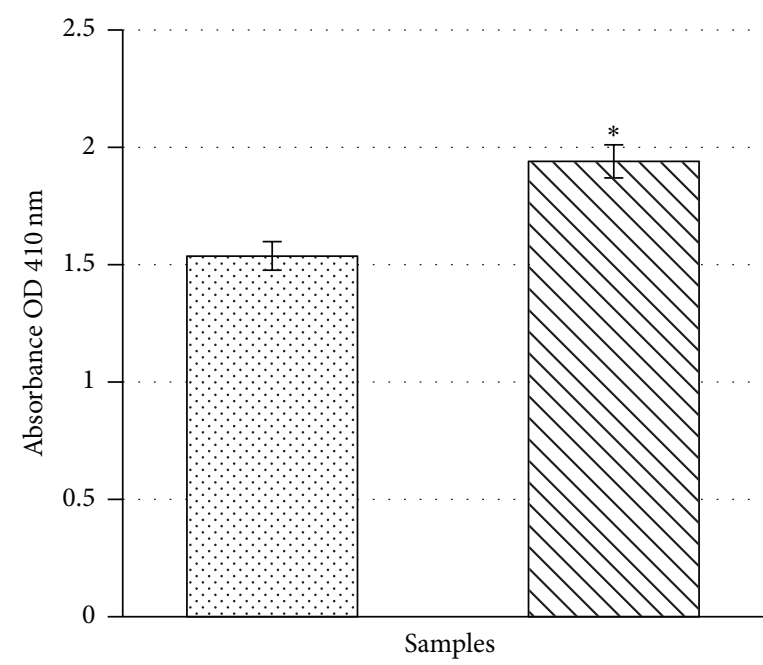

DNA/buffer

$\triangle 100$ nM Exotoxin A/buffer

(a)

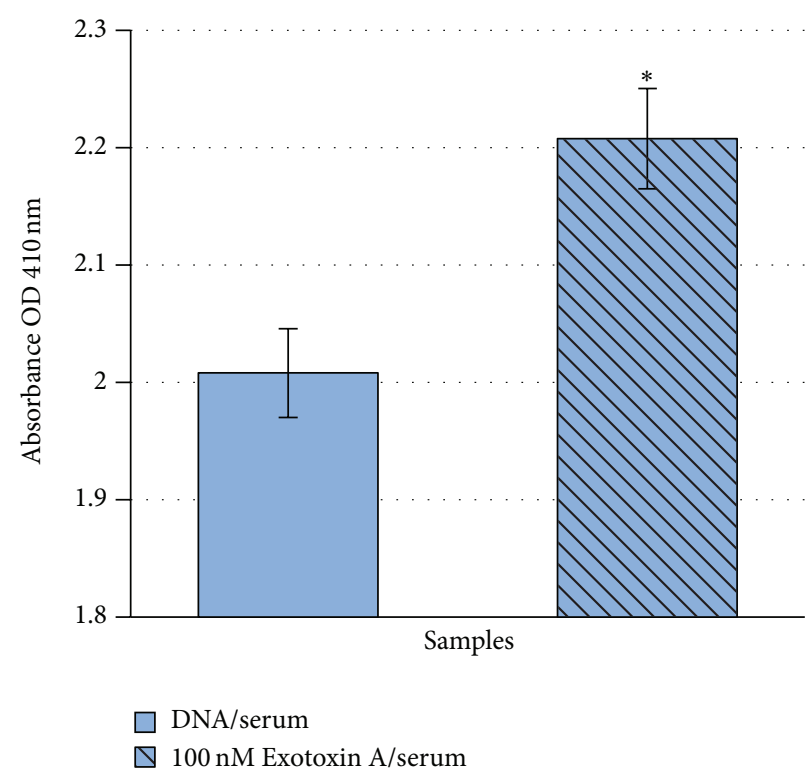

(b)

Figure 6: Modified ELISA assays of Exotoxin A. Data represent one modified sandwich ELISA with absorbance measured at OD $410 \mathrm{~nm}$. Absorbance levels presented are subtracted from background levels of blank well without immobilized DNA. Error bars represent standard deviations of 4 sample replicates in one independent assay. (a) Statistical significance levels with respect to buffer background of $P<0.001$ are designated by “*”. (b) Statistical significant levels with respect to human serum background of $P<0.001$ are designated by “ $*$ ”. Buffer: 1x selection buffer; serum: human serum.

Element specific for Exotoxin A, a virulence factor of Pseudomonas aeruginosa. The MRE is characterized to have high affinity and specificity to its target, thus validating the Decoy-SELEX methodology. It also showed sensitive detection of Exotoxin $\mathrm{A}$ at nanomolar concentrations in human serum through a modified sandwich ELISA assay and demonstrated the proof-of-principle diagnostic application of ssDNA MREs.

\section{Conflict of Interests}

The authors declare that there is no conflict of interests regarding the publication of this paper.

\section{Acknowledgments}

This work was supported by National Science Foundation Cooperative Agreements (NSF-100907 and NSF-0554328), Department of Defense Cooperative Agreement (W911NF09-2-0044), and West Virginia University. Ryan M. Williams was supported in part by a fellowship from the American Foundation for Pharmaceutical Education.

\section{References}

[1] O. R. Pavlovskis and F. B. Gordon, "Pseudomonas aeruginosa exotoxin: effect on cell cultures," Journal of Infectious Diseases, vol. 125, no. 6, pp. 631-636, 1972.

[2] A. E. Ballok and G. A. O'Toole, "Pouring salt on a wound: Pseudomonas aeruginosa virulence factors alter $\mathrm{Na}^{+}$and $\mathrm{Cl}^{-}$ flux in the lung," Journal of Bacteriology, vol. 195, no. 18, pp. 4013-4019, 2013.

[3] M. I. Gómez and A. Prince, "Opportunistic infections in lung disease: pseudomonas infections in cystic fibrosis," Current Opinion in Pharmacology, vol. 7, no. 3, pp. 244-251, 2007.

[4] G. Bennett, C. Dealey, and J. Posnett, "The cost of pressure ulcers in the UK," Age and Ageing, vol. 33, no. 3, pp. 230-235, 2004.

[5] D. P. Nichols, S. Caceres, L. Caverly et al., "Effects of azithromycin in Pseudomonas aeruginosa burn wound infection," Journal of Surgical Research, vol. 183, no. 2, pp. 767-776, 2013.

[6] M. Gu, J. Rappapor, and S. H. Leppla, "Furin is important but not essential for the proteolytic maturation of gp160 of HIV-1," FEBS Letters, vol. 365, no. 1, pp. 95-97, 1995.

[7] S. H. Leppla, "Large scale purification and characterization of the exotoxin of Pseudomonas aeruginosa," Infection and Immunity, vol. 14, no. 4, pp. 1077-1086, 1976.

[8] J. E. Wedekind, C. B. Trame, M. Dorywalska et al., "Refined crystallographic structure of Pseudomonas aeruginosa exotoxin A and its implications for the molecular mechanism of toxicity," Journal of Molecular Biology, vol. 314, no. 4, pp. 823-837, 2001.

[9] D. M. Gill, "Bacterial toxins: a table of lethal amounts," Microbiological Reviews, vol. 46, no. 1, pp. 86-94, 1982.

[10] B. H. Iglewski and J. C. Sadoff, "Toxin inhibitors of protein synthesis: production, purification, and assay of Pseudomonas aeruginosa toxin A," Methods in Enzymology, vol. 60, pp. 780793, 1979.

[11] D. Louis, P. Sorlier, and J. Wallach, "Quantitation and enzymatic activity of the alkaline protease from Pseudomonas aeruginosa in culture supernatants from clinical strains," Clinical Chemistry and Laboratory Medicine, vol. 36, no. 5, pp. 295-298, 1998. 
[12] Y. Morita, J. Tomida, and Y. Kawamura, "Responses of Pseudomonas aeruginosa to antimicrobials," Frontiers in Microbiology, vol. 4, article 422, 2014.

[13] D. De Vos, A. Lim Jr., J.-P. Pirnay et al., "Direct detection and identification of Pseudomonas aeruginosa in clinical samples such as skin biopsy specimens and expectorations by multiplex PCR based on two outer membrane lipoprotein genes, oprI and oprL," Journal of Clinical Microbiology, vol. 35, no. 6, pp. 12951299, 1997.

[14] R. Lavenir, D. Jocktane, F. Laurent, S. Nazaret, and B. Cournoyer, "Improved reliability of Pseudomonas aeruginosa PCR detection by the use of the species-specific ecfX gene target," Journal of Microbiological Methods, vol. 70, no. 1, pp. 2029, 2007.

[15] M. Motoshima, K. Yanagihara, K. Fukushima et al., "Rapid and accurate detection of Pseudomonas aeruginosa by real-time polymerase chain reaction with melting curve analysis targeting gyrB gene," Diagnostic Microbiology and Infectious Disease, vol. 58, no. 1, pp. 53-58, 2007.

[16] A. A. Khan and C. E. Cerniglia, "Detection of Pseudomonas aeruginosa from clinical and environmental samples by amplification of the exotoxin A gene using PCR," Applied and Environmental Microbiology, vol. 60, no. 10, pp. 3739-3745, 1994.

[17] A. V. Kolesnikova, A. V. Kozyr'b, and I. G. Shemyakinb, "The prospects for using aptamers in diagnosing bacterial infections," Molecular Genetics, Microbiology and Virology, vol. 27, no. 2, pp. 49-55, 2012.

[18] J. M. Gaines, N. L. Carty, J. A. Colmer-Hamood, and A. N. Hamood, "Effect of static growth and different levels of environmental oxygen on toxA and ptxR expression in the Pseudomonas aeruginosa strain PAO1," Microbiology, vol. 151, no. 7, pp. 2263-2275, 2005.

[19] J. M. Gaines, N. L. Carty, F. Tiburzi et al., "Regulation of the Pseudomonas aeruginosa toxA, regA and ptxR genes by the iron-starvation sigma factor PvdS under reduced levels of oxygen," Microbiology, vol. 153, no. 12, pp. 4219-4233, 2007.

[20] C. V. Gallant, T. L. Raivio, J. C. Olson, D. E. Woods, and D. G. Storey, "Pseudomonas aeruginosa cystic fibrosis clinical isolates produce exotoxin A with altered ADP-ribosyltransferase activity and cytotoxicity," Microbiology, vol. 146, no. 8, pp. 1891-1899, 2000.

[21] A. S. Cross, J. C. Sadoff, B. H. Iglewski, and P. A. Sokol, "Evidence for the role of toxin A in the pathogenesis of infection with Pseudomonas aeruginosa in humans," Journal of Infectious Diseases, vol. 142, no. 4, pp. 538-546, 1980.

[22] R. B. Moss, Y.-P. Hsu, N. J. Lewiston et al., "Association of systemic immune complexes, complement activation, and antibodies to Pseudomonas aeruginosa lipopolysaccharide and exotoxin A with mortality in cystic fibrosis," American Review of Respiratory Disease, vol. 133, no. 4, pp. 648-652, 1986.

[23] J. M. Zimbron, T. Heinisch, M. Schmid et al., "A dual anchoring strategy for the localization and activation of artificial metalloenzymes based on the biotin-streptavidin technology," Journal of the American Chemical Society, vol. 135, no. 14, pp. 5384-5388, 2013.

[24] A. Bujacz, "Structures of bovine, equine and leporine serum albumin," Acta Crystallographica Section D: Biological Crystallography, vol. 68, no. 10, pp. 1278-1289, 2012.

[25] C. J. O’Neal, M. G. Jobling, R. K. Holmes, and W. G. J. Hol, "Structural basis for the activation of cholera toxin by human ARF6-GTP," Science, vol. 309, no. 5737, pp. 1093-1096, 2005.
[26] M. Zuker, "Mfold web server for nucleic acid folding and hybridization prediction," Nucleic Acids Research, vol. 31, no. 13, pp. 3406-3415, 2003.

[27] C. Tuerk and L. Gold, "Systematic evolution of ligands by exponential enrichment: RNA ligands to bacteriophage T4 DNA polymerase," Science, vol. 249, no. 4968, pp. 505-510, 1990.

[28] L.-O. Andersson, "The heterogeneity of bovine serum albumin," Biochimica et Biophysica Acta, vol. 117, no. 1, pp. 115-133, 1966.

[29] N. K. Ganguly and T. Kaur, "Mechanism of action of cholera toxin and other toxins," Indian Journal of Medical Research, vol. 104, pp. 28-37, 1996.

[30] T. Nguyen, R. Pei, D. W. Landry, M. N. Stojanovic, and Q. Lin, "Microfluidic aptameric affinity sensing of vasopressin for clinical diagnostic and therapeutic applications," Sensors and Actuators B: Chemical, vol. 154, no. 1, pp. 59-66, 2011.

[31] J. S. Swensen, Y. Xiao, B. S. Ferguson et al., "Continuous, realtime monitoring of cocaine in undiluted blood serum via a microfluidic, electrochemical aptamer-based sensor," Journal of the American Chemical Society, vol. 131, no. 12, pp. 4262-4266, 2009.

[32] H. Wang, Y. Liu, C. Liu, J. Huang, P. Yang, and B. Liu, "Microfluidic chip-based aptasensor for amplified electrochemical detection of human thrombin," Electrochemistry Communications, vol. 12, no. 2, pp. 258-261, 2010.

[33] T. Hultman, S. Stahl, E. Hornes, and M. Uhlen, "Direct solid phase sequencing of genomic and plasmid DNA using magnetic beads as solid support," Nucleic Acids Research, vol. 17, no. 13, pp. 4937-4946, 1989.

[34] K. L. Hong, L. Battistella, A. D. Salva, R. M. Williams, and L. J. Sooter, "In vitro selection of single-stranded DNA molecular recognition elements against $S$. aureus alpha toxin and sensitive detection in human serum," International Journal of Molecular Sciences, vol. 16, no. 2, pp. 2794-2809, 2015.

[35] K. L. Hong, E. Maher, R. M. Williams, and L. J. Sooter, "In vitro selection of a single-stranded dna molecular recognition element against Clostridium difficile toxin $\mathrm{b}$ and sensitive detection in human fecal matter," Journal of Nucleic Acids, vol. 2015, Article ID 808495, 12 pages, 2015.

[36] J. Ashley and S. F. Li, "An aptamer based surface plasmon resonance biosensor for the detection of bovine catalase in milk," Biosensors and Bioelectronics, vol. 48, pp. 126-131, 2013.

[37] Y. Liu and W. D. Wilson, "Quantitative analysis of small molecule-nucleic acid interactions with a biosensor surface and surface plasmon resonance detection," Methods in Molecular Biology, vol. 613, pp. 1-23, 2010.

[38] R. M. Williams, C. L. Crihfield, S. Gattu, L. A. Holland, and L. J. Sooter, "In vitro selection of a single-stranded DNA molecular recognition element against atrazine," International Journal of Molecular Sciences, vol. 15, no. 8, pp. 14332-14347, 2014.

[39] D. J. Patel, A. K. Suri, F. Jiang et al., "Structure, recognition and adaptive binding in RNA aptamer complexes," Journal of Molecular Biology, vol. 272, no. 5, pp. 645-664, 1997.

[40] N. Duan, X. Ding, L. He, S. Wu, Y. Wei, and Z. Wang, "Selection, identification and application of a DNA aptamer against Listeria monocytogenes," Food Control, vol. 33, no. 1, pp. 239-243, 2013.

[41] S. J. Lee, B. S. Youn, J. W. Park, J. H. Niazi, Y. S. Kim, and M. B. Gu, "ssDNA aptamer-based surface plasmon resonance biosensor for the detection of retinol binding protein 4 for the early diagnosis of type 2 diabetes," Analytical Chemistry, vol. 80, no. 8 , pp. $2867-2873,2008$. 
[42] D. T. Tran, K. Knez, K. P. Janssen, J. Pollet, D. Spasic, and J. Lammertyn, "Selection of aptamers against Ara h 1 protein for FO-SPR biosensing of peanut allergens in food matrices," Biosensors and Bioelectronics, vol. 43, no. 1, pp. 245-251, 2013.

[43] R. Wang, J. Zhao, T. Jiang et al., "Selection and characterization of DNA aptamers for use in detection of avian influenza virus H5N1," Journal of Virological Methods, vol. 189, no. 2, pp. 362369, 2013.

[44] J. Pollet, F. Delport, K. P. F. Janssen et al., "Fiber optic SPR biosensing of DNA hybridization and DNA-protein interactions," Biosensors and Bioelectronics, vol. 25, no. 4, pp. 864-869, 2009.

[45] C.-C. Chang, S. Lin, C.-H. Lee et al., "Amplified surface plasmon resonance immunosensor for interferon-gamma based on a streptavidin-incorporated aptamer," Biosensors and Bioelectronics, vol. 37, no. 1, pp. 68-74, 2012.

[46] J.-W. Park, S. Jin Lee, E.-J. Choi, J. Kim, J.-Y. Song, and M. Bock $\mathrm{Gu}$, "An ultra-sensitive detection of a whole virus using dual aptamers developed by immobilization-free screening," Biosensors and Bioelectronics, vol. 51, pp. 324-329, 2014.

[47] P. S. Katsamba, S. Park, and I. A. Laird-Offringa, "Kinetic studies of RNA-protein interactions using surface plasmon resonance," Methods, vol. 26, no. 2, pp. 95-104, 2002.

[48] A. Shoji, M. Kuwahara, H. Ozaki, and H. Sawai, "Modified DNA aptamer that binds the (R)-isomer of a thalidomide derivative with high enantioselectivity," Journal of the American Chemical Society, vol. 129, no. 5, pp. 1456-1464, 2007.

[49] R. R. White, B. A. Sullenger, and C. P. Rusconi, "Developing aptamers into therapeutics," The Journal of Clinical Investigation, vol. 106, no. 8, pp. 929-934, 2000.

[50] J.-W. Park, S. S. Kallempudi, J. H. Niazi, Y. Gurbuz, B.-S. Youn, and M. B. Gu, "Rapid and sensitive detection of Nampt (PBEF/visfatin) in human serum using an ssDNA aptamerbased capacitive biosensor," Biosensors and Bioelectronics, vol. 38, no. 1, pp. 233-238, 2012.

[51] J. G. Bruno and J. L. Kiel, "Use of magnetic beads in selection and detection of biotoxin aptamers by electrochemiluminescence and enzymatic methods," BioTechniques, vol. 32, no. 1, pp. 178-183, 2002.

[52] J. S. Choi, S. G. Kim, M. Lahousse et al., "Screening and characterization of high-affinity ssDNA aptamers against anthrax protective antigen," Journal of Biomolecular Screening, vol. 16, no. 2, pp. 266-271, 2011.

[53] S. Dayton, S. Hashimoto, W. Dixon, and M. L. Pearce, "Composition of lipids in human serum and adipose tissue during prolonged feeding of a diet high in unsaturated fat," Journal of Lipid Research, vol. 7, no. 1, pp. 103-111, 1966.

[54] N. Furuya, Y. Hirakata, K. Tomono et al., "Mortality rates amongst mice with endogenous septicaemia caused by Pseudomonas aeruginosa isolates from various clinical sources," Journal of Medical Microbiology, vol. 39, no. 2, pp. 141-146, 1993.

[55] Y. Hirakata, N. Furuya, K. Tateda, M. Kaku, and K. Yamaguchi, "In vivo production of exotoxin A and its role in endogenous Pseudomonas aeruginosa septicemia in mice," Infection and Immunity, vol. 61, no. 6, pp. 2468-2473, 1993.

[56] M. C. Jaffar-Bandjee, A. Lazdunski, M. Bally, J. Carrere, J. P. Chazalette, and C. Galabert, "Production of elastase, exotoxin $\mathrm{A}$, and alkaline protease in sputa during pulmonary exacerbation of cystic fibrosis in patients chronically infected by Pseudomonas aeruginosa," Journal of Clinical Microbiology, vol. 33, no. 4, pp. 924-929, 1995.
[57] D. E. Woods, M. S. Schaffer, H. R. Rabin, G. D. Campbell, and P. A. Sokol, "Phenotypic comparison of Pseudomonas aeruginosa strains isolated from a variety of clinical sites," Journal of Clinical Microbiology, vol. 24, no. 2, pp. 260-264, 1986.

[58] M. J. Bjorn, B. H. Iglewski, S. K. Ives, J. C. Sadoff, and M. L. Vasil, "Effect of iron on yields of exotoxin A in cultures of Pseudomonas aeruginosa PA-103," Infection and Immunity, vol. 19, no. 3, pp. 785-791, 1978.

[59] M. J. Bjorn, P. A. Sokol, and B. H. Iglewski, "Influence of iron on yields of extracellular products in Pseudomonas aeruginosa cultures," Journal of Bacteriology, vol. 138, no. 1, pp. 193-200, 1979.

[60] D. W. Chung and R. J. Collier, "Enzymatically active peptide from the adenosine diphosphate-ribosylating toxin of Pseudomonas aeruginosa," Infection and Immunity, vol. 16, no. 3, pp. 832-841, 1977.

[61] K. M. You, S. H. Lee, A. Im, and S. B. Lee, "Aptamers as functional nucleic acids: in vitro selection and biotechnological applications," Biotechnology and Bioprocess Engineering, vol. 8, no. 2, pp. 64-75, 2003. 

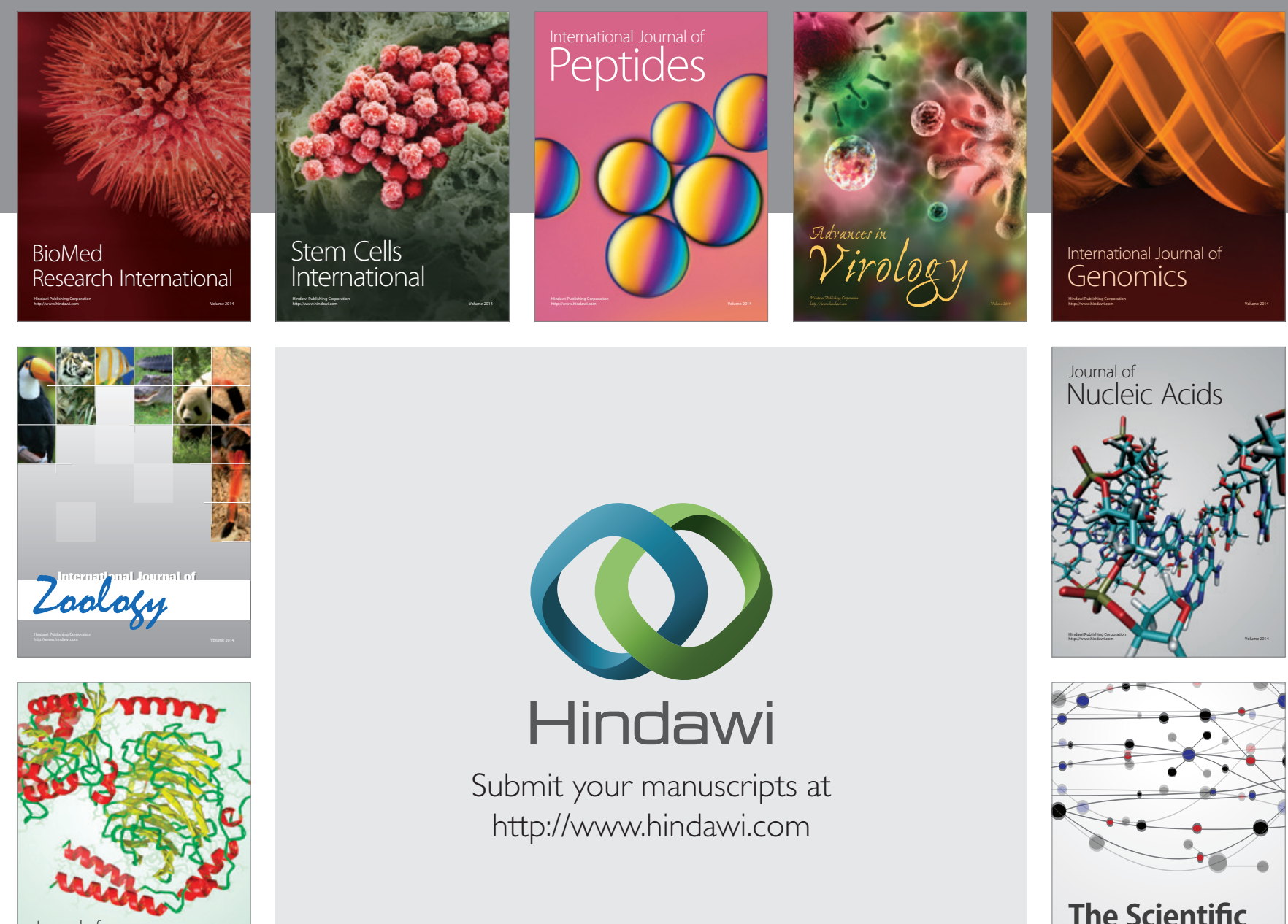

Submit your manuscripts at

http://www.hindawi.com

Journal of
Signal Transduction
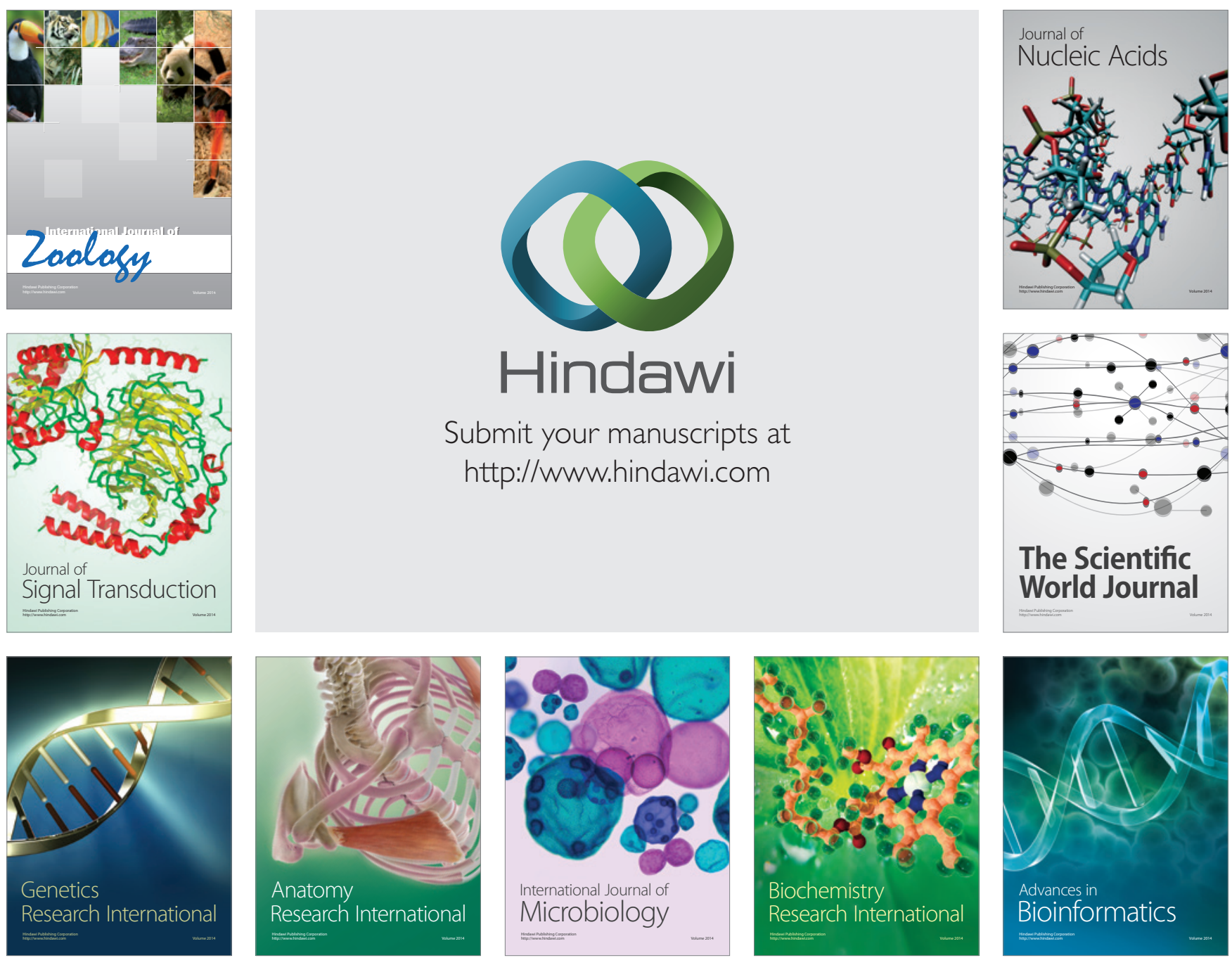

The Scientific World Journal
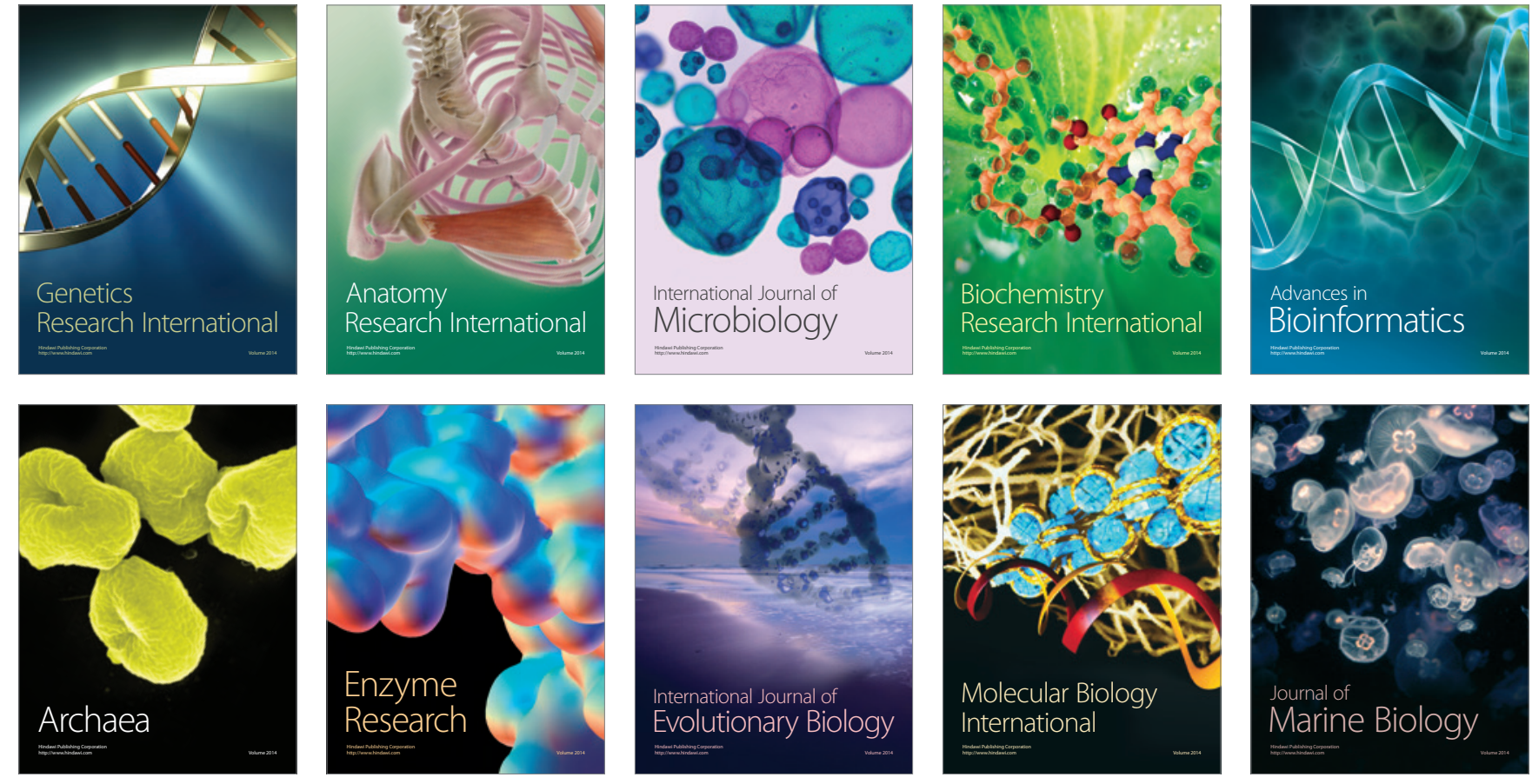